Portland State University

PDXScholar

7-14-1978

\title{
An Analysis of Staggered Spondaic Word Test Performances of Dyslexic Children and Their Parents
}

Nancy Jane Maxwell

Portland State University

Follow this and additional works at: https://pdxscholar.library.pdx.edu/open_access_etds

Part of the Genetics Commons, and the Speech Pathology and Audiology Commons Let us know how access to this document benefits you.

Recommended Citation

Maxwell, Nancy Jane, "An Analysis of Staggered Spondaic Word Test Performances of Dyslexic Children and Their Parents" (1978). Dissertations and Theses. Paper 2734.

https://doi.org/10.15760/etd.2733

This Thesis is brought to you for free and open access. It has been accepted for inclusion in Dissertations and Theses by an authorized administrator of PDXScholar. Please contact us if we can make this document more accessible: pdxscholar@pdx.edu. 
AN ABSTRACT OF THE THESIS OF Nancy Jane Maxwell for the Master of Science in Speech Communication presented July $14,1978$.

Title: An Analysis of Staggered Spondaic Word Test Performances of Dyslexic Children and Their Parents.

APPROVED BY MEMBERS OF THE THESIS COMMITTEE:

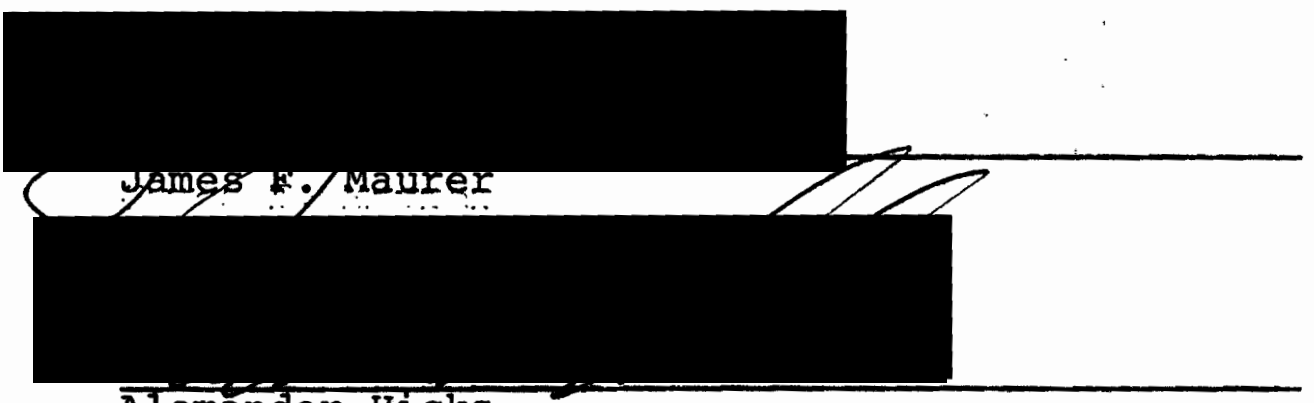

Alamănder Hicks

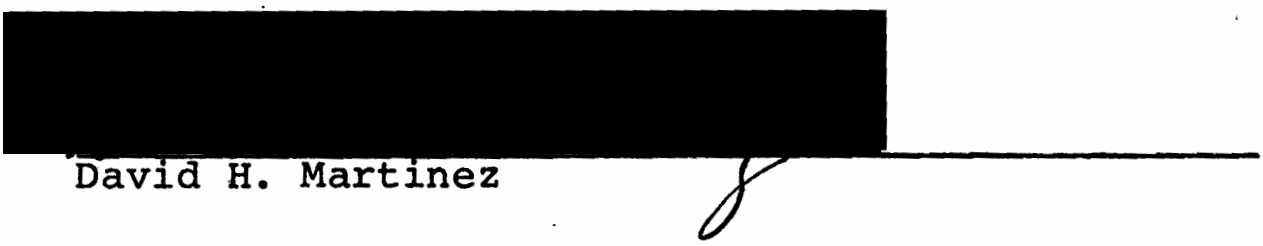

The purpose of this study was to investigate the possibility of a familial lineage for dyslexia by analyzing certain auditory processing characteristics of dyslexic children and their parents. The staggered Spondaic Word test was administered to twenty-one dyslexic children, eight to thirteen years of age, their natural parents and normal reading siblings. 
The experimental test data were tabulated and analyzed according to listening condition for each of the four groups: dyslexic children, normal reading siblings, affected parents and non-affected parents. A statistical analysis of the experimental data revealed significantly poorer Staggered Spondaic Word test performances for dyslexic children and their affected parents, in both the right and left competing listening conditions, when compared to test performances of their normal reading siblings and non-affected parents. These test results appear to support a genetic precursor theory for dyslexia. The experimental findings from the present investigation are discussed in terms of their clinical implications for the identification and management of dyslexic children. 
AN ANALYSIS OF STAGGERED SPONDAIC WORD TEST PERFORMANCES OF DYSLEXIC CHILDREN AND THEIR PARENTS

by

NANCY JANE MAXWELL

A thesis submitted in partial fulfillment of the requirements for the degree of

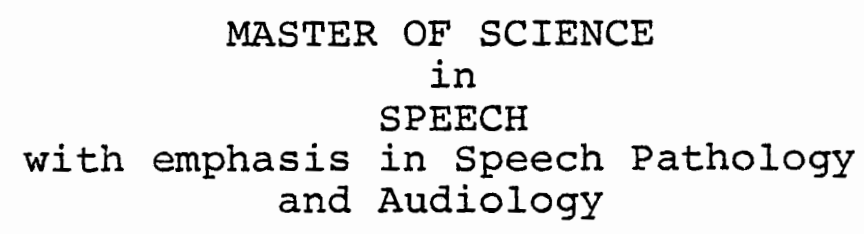

Portland State University

1978 
TO THE OFFICE OF GRADUATE STUDIES AND RESEARCH:

The members of the committee approve the thesis

of Nancy Jane Maxwell presented July 14, 1978.

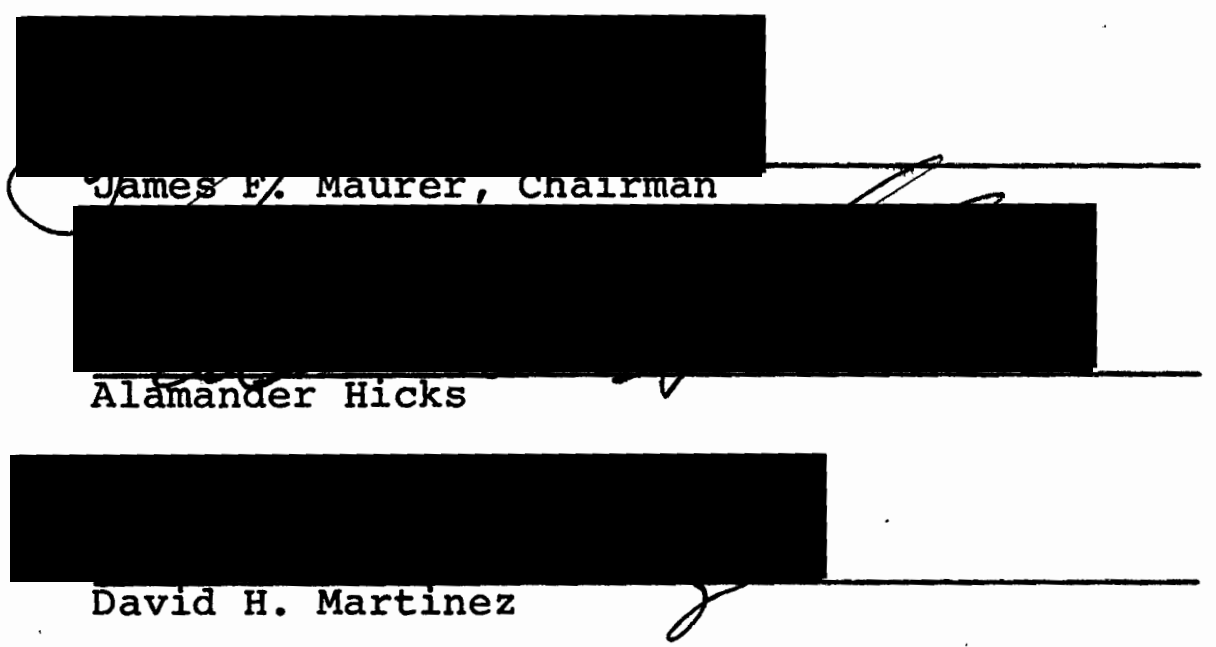

APPROVED :

Rbbert W. Vogdusang, Hefa, Department of Speech Communication Stanley E. Rauch, Dean of Graduate Studies and Research 


\section{ACKNOWLEDGEMENTS}

I wish to express my sincere thanks and appreciation to Dr. James F. Maurer, my thesis committee chairman, for the unremitting guidance and encouragement that made this investigation possible. A special thanks for his unfailing enthusiasm and faith in this study when it was needed most.

My deepest and most sincere gratitude is extended to Dr. Al Hicks, my advisor, for his whole hearted support, encouragement and technical assistance throughout this investigation - a very special thanks to an exceptional teacher.

I wish to acknowledge the support and guidance given by Dr. David Martinez in the practical application of the results from this investigation.

Finally, I wish to thank my husband Dennis for his friendship and support throughout this period. 
TABLE OF CONTENTS

PAGE

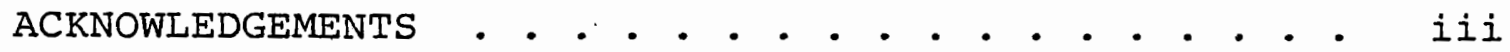

LIST OF TABLES . . . . . . . . . . . . . . . V v

LIST OF FIGURES . . . . . . . . . . . . . . . . v vi

CHAPTER

I INTRODUCTION . . . . . . . . . . . 1

II REVIEW OF THE IITERATURE . . . . . . . . . 3

Purpose . . . . . . . . . . 21

Null Hypothesis . . . . . . . 22

III METHOD ................ 23

Subjects . . . . . . . . . . 23

Procedure ............ 24

Instrumentation ........ . 26

Data ............ . 27

IV RESULTS . . . . . . . . . . . 30

$\mathrm{V}$ DISCUSSION ............. . . 41

Conclusion ........... . . 47

Implications for Further Research. . . 48

A SELECTED BIBLIOGRAPHY . . . . . . . . . . . . 50

APPENDICES .................. . . 56 


\section{IIST OF TABLES}

TABLE

PAGE

I Mean Percentage SSW Test Scores for All

Subjects Iisted According to Iistening

Condition . . . . . . . . . . . . •

II Mean Percentage SSW Scores, Standard

Deviations, and t-Values for Dyslexic

Children and Affected Parents Iisted

According to Listening Condition .....

II Mean Percentage SSW Scores, Standard

Deviations, and $t$-Values for Dyslexic

Children and Non-affected Parents Listed

According to Listening Condition . . . . 34

IV Mean Percentage SSW Scores, Standard

Deviations, and $t$-Values for Affected

and Non-affected Parents Listed According

to Iistening Condition . . . . . . . .

V Mean Percentage SSW Scores, Standard

Deviations, and $t$-Values for Dyslexic

Children and Normal Reading Siblings

Iisted According to Listening

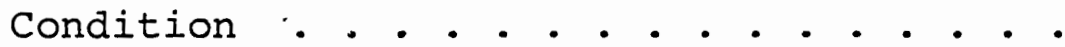




\section{IIST OF FIGURES}

FIGURE

PAGE

1. Sample of Two SSW Test Items Illustrating Temporal Presentation and Reversal of Leading Ear • • • • • . • . • • • 18

2. Schematic Diagram of Experimental Instrumentation . . . . . . . . . . 28

3. Mean SSW Test Errors for Affected and Non-affected Parents as a Function of Iistening Condition . . . . . . . . 36

4. Mean SSW Test Errors of Dyslexic Children and Normal Reading siblings as a Function of Listening Condition . . . . . . . . .

5. Comparison of Mean Correct Responses as a Function of Iistening Condition for All Experimental Groups . . . . . . .

6. Comparison of Mean Correct Responses as a Function of Listening Condition for Dyslexic Children and Affected Parents and Normative Data for Adults and Children . . . . . . . . . . . . . 
CHAPTER I

INTRODUCTION

Millions of children in this country are classified as "learning disabled" by their classroom teacher or learning specialist in the school. Very generally, the term learning disability refers to the existence of a measurable discrepancy between academic performance and an anticipated potential. This performance deficit may manifest itself in impaired ability to attend to task, to conceptualize, to speak or communicate clearly, to read with comprehension, to write legibly with meaning, to spell accurately, or to perform mathematical calculations including those involving reading (Mercer, 1976; Merifield, 1970; Silver, 1971).

A large portion of these learning disabled children manifest a partial inability to learn to read, and thus may be considered "dyslexic." It is estimated that dyslexia occurs in 5 to 10 percent of all children, with boys affected up to five times more often than girls (Critchley, 1970; Merifield, 1970).

Professionals in the area of learning disabilities have proposed a definition of reading incompetence as a "significant discrepancy between the expected reading level and the child's actual reading level." A delay of one year 
is considered diagnostic in children up to ten years of age, and two years delay in children older than ten years (Rosenthal, 1973).

The earliest research dealing with reading disabilities dates back to the turn of the century and simply consisted of case identification and descriptions (Critchley, 1970). More recently, investigators have focused on the emotional and neurological correlates of "dyslexia" (Klasen, 1972; White, 1973). However, to date researchers have failed to report specific etiological factors responsible for reading dysfunction. That is, questions dealing with emotional, neurological, and hereditary correlates of "dyslexia" remain unanswered. 
CHAPTER II

REVIEW OF THE IITERATURE

The literature dealing with dyslexia is complicated by the fact that there is little agreement among. researchers with respect to terminology. The following terms were noted in the readings: "reading-spelling weakness"; "reading retardation"; "reading problem"; "word blindness"; "visual dyslexia"; "auditory dyslexia"; "literal dyslexia"; "verbal dyslexia"; "primary and secondary dyslexia"; "isolated, pure, dyphasic and Iinear dyslexia" (Critchley, 1970; Klasen, 1972; Spreen, 1970; White, 1973). As this enumeration demonstrates, the terminology used to discuss the disorder is not based on equal principles but rather on points of interest., such as etiology, symptomatology, degree, etc.

These differences in opinion concerning the symptomatology and etiology of dyslexia have led to a multiplicity of systems of classification for reading disorder. Many of these systems present a logically inconsistent and confusing combination of symptomatic and etiologic criteria. All of these classification systems reflect the bias of the professional discipline from which they emanate and have thus led many professionals in this area to doubt the existence of a clear-cut group of disorders (U.S. Department of 
Health, Education and Welfare, 1969). This diversity of approaches has resulted in disagreement regarding the meaning of the term "dyslexia." By derivation the term simply means a disorder of reading (Wood, 1971).

The World Federation of Neurology, Research Group on Developmental Dyslexia and World Illiteracy adopted a definition in 1968 which they recommended for general acceptance (Critchley, 1970):

Dyslexia: A disorder in children who, despite conventional classroom experience, fail to attain the language skills of reading, writing, and spelling commensurate with their intellectual abilities.

Dyslexia is characterized, then, by the presence of a large disparity between a child's reading ability and his intellectual ability with no obvious concomitant variables. That is, the essential diagnostic component is the demonstration of a disparity between intelligence and the ability to read in a child who has had an adequate opportunity to learn to read (Critchley, 1970; Manson, 1975; White, 1973). Reading is a complex skill which depends on processing written phonetic, syntactic, and semantic information in response to a visual-graphic display. Reading is thus a form of language which is dependent on specific associations between various sensory processing centers in the brain. Research of language functions in general, and reading in particular, indicate that there must be adequate association between the dominant visual center (believed to be in the right hemisphere) and the speech and language area (in the 
left) (Gazzangia and Sperry, 1967; Masland, 1970; StuddertKennedy and Shankweiler, 1970). The written word and the visually or tactuaily presented object must arouse their appropriate auditory associates if they are to be successfully read or named (Masland, 1970).

Since reading is clearly dependent on vision and audition, knowledge of the central processing of visual and auditory stimuli is essential to an understanding of this disordered language process. Gazzangia and Sperry (1967) investigated the visual processing and language abilities of patients after surgical separation of the cerebral commisures. These researchers concluded that visual processing occurs in both hemispheres of the brain, with the right hemisphere capable of integrating and conceptualizing the information presented to both visual fields. The right hemisphere may also be responsible for spatial orientation (Warrington and Kinsbourne, 1966).

Visual processing occurs primarily in the hemisphere contralateral ${ }^{1}$ to the eye receiving the stimuli (Gazzangia and Sperry, 1967). Words which were presented to the left visual field (right hemisphere) of these patients with severed commisures resulted in a verbal denial that anything was presented. When the patient was encouraged to choose

${ }^{1}$ Contralateral refers to the association with a part on the opposite side (Wood, 1971). In this case, the left hemisphere processes all visual information presented to the right half of the visual fiela. 
an object which matched the word, the left hand was able to correctly match the object with the word at all times. When the word was presented exclusively to the right visual field (left hemisphere) the patient verbalized seeing a word but was unable to identify the word at a level greater than chance. Correct matching of the word with the corresponding object also occurred less than half the time. Further, Gazzangia and Sperry reported that information perceived exclusively in the right hemisphere could not be communicated in speech or writing, but had to be expressed entirely through non-verbal responses.

Auditory processing of speech stimuli occurs predominantly in the left hemisphere (Studdert-Kennedy and Shankweiler, 1970). These authors reason that a distinction must be made between the extraction of the speech parameters from an auditory signal and the linguistic "interpretation" of these parameters. The dominant cerebral hemisphere (which is believed to be the left hemisphere for most people) appears to be equipped with the specialized processing required to "interpret" the speech components of a message, while the processing of acoustic information is the domain of the general auditory system common to both hemispheres. That is, while the dominant hemisphere encodes auditory speech stimuli, these researchers maintain that for non-speech stimuli, the right hemisphere plays a greater role than the left in the recognition of auditory patterns 
and the discrimination of their various attributes. Studdert-Kennedy and Shankweiler conclude that each hemisphere can perform an auditory pattern analysis without aid from the other, but only the isolated left hemisphere can complete the perceptual process of interpretation of these patterns as a set of linguistic features.

While some researchers believe that reading disorders are either visual or auditory deficits, investigations of the integrative nature of language have led most researchers to conclude that dyslexic children appear to sustain a breakdown in the integration of information between these two sensory modalities (Critchley, 1970; Holroyd, 1968; Satz, 1970). Defective visual or spatial conceptualization strongly suggests impaired processing in the right hemisphere of the brain (Gazzangia and Sperry, 1967), while defective verbal or conceptual labeling suggests an alteration in language processing which is heavily dependent on the development of the left hemisphere (Lenneberg, 1967). Since reading is a process which involves active participation of both hemispheres in decoding and encoding written Iinguistic elements, it is not surprising to note that the associated behavioral deficits evidenced by dyslexic children are primarily in the areas of processing and producing language.

Several behavioral deficits are often associated with dyslexia. Among them may be a reduced ability to 
discriminate phonemic stimuli, an inability to apply verbal labels to visual and auditory stimuli, abnormal processing of auditory stimuli, right-left confusion, and the lack of a firm cerebral dominance (Belmont and Birch, 1965; Bettman et al., 1967; Blank and Bridger, 1966; Critchley, 1970; Johnson, 1972; Orton, 1937; Shepard, 1956; Silver and Hagen, $1960)$.

Some dyslexic children demonstrate a reduced ability to discriminate phonemic stimuli. Oakland (196.9) presented data indicating that dyslexic children demonstrate poor performance on auditory discrimination tasks requiring the child to indicate whether nonsense syllables were the same or different. In a similar discrimination task utilizing pure tones and meaningless noise, Oakland observed that the performance of these children was normal, suggesting an inadequate ability to synthesize phonemic elements of ianguage rather than a general disfunction in auditory processing.

Mulder and Curtin (1955) administered a phonemic synthesis (PS) test to sixty-three fourth-grade children, including both normal readers and dyslexics. The correlation between the PS test and reading ability was significant at the 0.01 level of confidence. These researchers concluded that poor readers were deficient in their ability to synthesize phonemes into meaningful words.

Blank and Bridger (1966) found that retarded readers experienced difficulty applying verbal labels to referent 
stimuli. It was noted that no difference was found when the stimuli were presented in either visual or auditory form. These findings again suggest difficulty encoding language.

Further support for the findings of poor language processing among dyslexic subjects is presented by Mulder and Curtin (1955) who observed a reduced ability to verbalize concepts and thoughts among dyslexic children. These researchers also reported poor writing-spelling skills among these children, with reversals and delayed proficiency in combining. phonetic elements to. form words. Holroyd (1967) presented evidence of spontaneous spelling impairments among dyslexic children. In addition, difficulty using vocabulary effectively was noted.

Dyslexic children demonstrate unique performances in dichotic ${ }^{2}$ listening tasks. Johnson (1972) administered a set. of words and nonsense syllables in a dichotic mode to both dyslexics and normal readers. She noted that normal readers. appeared to attend to one or the other channel but not to both. Dyslexic children, on the other hand, attempted and often succeeded in receiving both sets of stimuIi and tried to integrate the discordant messages. Johnson suggested that the abnormal performance by the dyslexic subjects may be due to the lack of a weIl-defined cerebral

2 Dichotic refers to the condition in which sound stimulus presented at one ear differs from the stimulus presented to the other ear. The stimuli may differ in one or more acoustic parameters (Yost and Neilsen, 1977). 
dominance. She reasoned that since a dominant hemisphere for listening tasks in normals is well established, the dyslexics may break down in the integration of information between the two hemispheres, with both hemispheres trying to function independently.

Children with significant reading disorders often demonstrate an inability to identify right and left with reference to parts of their own bodies and to the general environment (Belmont and Birch, 1965). These authors insist that right-left confusions are not to be mistaken for the lack of a firm cerebral dominance. Rather, right-left confusion refers only to an inability to identify right and left parts of a system, whether it be their own body or a part of the immediate environment.

Lack of a well-established hemispherical dominance has been noted in some dyslexic children (Bakker, 1967; Johnson, 1972; Satz, 1965; Silver and Hagen, 1960). Normal readers typically have a dominant hemisphere for eye, hand, and foot functions. Dyslexics, however, are often found to have "mixed" dominance. The child might prove to be righteyed, left-handed, and right-footed. Any such combination can occur, and suggests the lack of a well-established hemispherical dominance (Bryden, 1970; Critchley, 1970; Drew, 1956).

Since language processing is believed to be consummated in the left hemisphere of the brain and reading is 
a form of language processing, the presence of "mixed" dominance has been thought by some researchers to be a causal factor in reading disfunction (Critchley, 1970; White, 1973). Any discussion of "mixed" dominance as an etiological factor must be approached with caution since "mixed" dominance does not characterize all dyslexics (Bettman, et al., 1967). This researcher noted that "mixed" dominance is present in both normal and in dyslexic populations, but the probability is greater that it will occur among dyslexics. Similarly, Belmont and Birch (1965) observed significant findings of "mixed" dominance in subjects drawn from clinic populations but not found when school populations are sampled. Finally, since "mixed" dominance is not a constant correlate of congenital dyslexia, Drew (1956) suggests that "mixed" dominance is possibly the result of a larger, more basic disturbance rather than a primary etiological factor. Although the relationship between neurological function and observed behavioral deficits of dyslexics remain tenuous, researchers continue to investigate possible causes and sites of lesion. In addition to the consideration of visual and auditory processing in normals, investigators have attempted to provide etiologic and genetic data by considering cross-modal integration in subjects with confirmed neurological impairments (Butters and Brody, 1968; Geshwind, 1965; Satz, 1965). 
Bocca and Calearo (1963) explain "literal visualauditory" dysfunction as inadequate auditory processing. They hypothesized that the joining together of auditory fibers from opposite sides into the same tract at the level of the brain stem may be imperfect, resulting in garbled auditory perception at the cognitive level. Thus, these researchers postulate that the lesion may be at the level of the brain stem and not higher in the cortex as most researchers believe. They place the site of lesion in the pulvinar ${ }^{3}$ (in the thalamus) because it receives collateral fibers from the auditory and visual nerves and sends them to the supramarginal and angular gyri of the parietal cortex (believed to be important in reading and other symbolic activities).

Butters and Brody (1968) investigated the relationship between the left inferior parietal cortex (angular gyrus) and cross-modal 4 association tasks in an adult population of confirmed brain lesions. These researchers found that the lesions invading the left inferior parietal cortex resulted in selective impairment on cross-modal tasks, particularly in the auditory-visual associations. The patients

$3_{\text {The pulvinar is the rounded prominence which forms }}$ the posterior surface of the thalamus. The pulvinar is continuous with the external geniculate body (Gray, 1974).

${ }^{4}$ Cross-modal refers to the necessity of integrating information from two distinct associative areas in the brain; in this case the visual and auditory processing areas. 
with "severe" parietal signs not only had difficulty with cross-modal matching tasks but also demonstrated an impaired ability to read. However, lesions in the right parietal cortex do not have the same effect on cross-modal matching tasks (Satz, 1965).

It has been proposed that the left inferior parietal lobe, in the region of the angular gyrus, receives afferent ${ }^{5}$ inputs from the visual, auditory, and somatosensory association cortices of both hemispheres of the brain and thereby mediates intersensory integration (Geshwind, 1965). Given this, Satz (1965) reasons that a lesion in this region of the visual and/or somatosensory inputs from the dominant speech hemisphere may well interfere with reading performance.

While research to date has failed to provide substantial evidence for a specific neurological determinant for dyslexia, a growing body of literature has provided compelling evidence that the dysfunction is hereditary in nature. Two lines of evidence strongly support the genetic basis for dyslexia: familial incidence and sex ratios (Critchley, 1970; Satz and Sparrow, 1970; White, 1973).

Hallgren (1950) reported one of the most significant studies on dyslexia to date. He examined 276 children with

${ }^{5}$ Afferent fibers are sensory nerves which carry information from the peripheral sense organ to the brain. This is opposed to efferent fibers which bring information to the periphery from the brain (Yost and Neilsen, 1977). 
diagnosed dyslexia and their families. In this study 88 percent of all subjects responding to questionnaires and interviews reported reading problems in one or more relatives. Hallgren concluded that this evidence provided a high probability that the dysfunction is hereditary in nature. These results must be viewed with caution since the results are based on post hoc questionnaires rather than objective measures.

Research with twins further supports a genetic mode of transmission. Hallgren (1950) reported a high correlation between monozygotic twins who demonstrated dyslexia. This correlation drops to 33 percent between dyzygotic twins.

Additional evidence which strongly supports a genetic basis for dyslexia is the disproportionate ratio of males to females who evidence this disorder. It has been observed that dyslexia affects males more often than females by a ratio of four or five to one (Critchley, 1970; Hallgren, 1950; Mykelbust and Johnson, 1962; Orton, 1935).

The genetic orientation regarding the etiology of dyslexia follows two lines of thought: one considers dyslexia to be the product of an inherited dysfunction or lesion of specific cerebral areas, such as the parietal or occipital lobes; ${ }^{6}$ the other is that dyslexia represents a reduction

6 This theory is supported by the observation that brain damage in the parietal or occipital lobes produces 
in the overall neurological maturation which manifests itself in a lack of cerebral integration (Satz, 1970; White, 1973) . .

The contention that dyslexia is caused by a lack of maturation of the cortical structures maintains that cerebral dominance does not develop as it does in a normal child (Satz, 1965; White, 1973). A maturational lag of the whole left hemisphere is assumed by Satz and Sparrow (1970) to be the underlying cause of dyslexia. Their hypothesis assumes that the child will outgrow the disorder and accepts a genetic predisposition for a maturational lag.

The relationship between reading and linguistic processing, and the apparent genetic involvement in disordered reading suggest the existence of a specific central involvement which should be detectable through the utilization of formal test procedures. Unfortunately, there are no reported formal tests which demonstrate a clear correlation between neurological involvement and dyslexia. The utilization of standardized test procedures provides a method of assessing the integrity of the central auditory pathways, a system which is vital to the encoding of phonemic elements necessary for reading. These test measures may provide a means of identifying and assessing dyslexic subjects. alexia, a complete inability to read (Butters and Brody, 1968). 
Audiologic measures for the evaluation of lesions in the central auditory pathways are established and demonstrate varying degrees of success. Conventional pure tone and speech audiometry do not identify "cortical" auditory impairments (Katz, 1962). Audiologically, disorders in the central auditory nervous system can be demonstrated by requiring the patient to evaluate an unusually difficult listening task. Presentation of a degrade speech stimulus which is characterized by a lack of extrinsic redundancy places a burden on the higher auditory pathways, and a weakness in integrative function is manifested in an inability to utilize the stimuli appropriately.

Bocca et al. (1955) presented arguments for employing distorted speech stimuli in an effort to require full use of the integrative processes of the central auditory system. They employed several techniques for distorting the speech signal: (1) low-frequency filtering of the signal;

(2) acceleration of the speech signal; and (3) speech switched periodically from ear to ear at a rapid rate. The work of Bocca has been expanded into three or four general approaches for identifying central auditory lesions utilizing speech stimuli: one challenges the higher auditory pathways by presenting less than a complete message to a subject, thus requiring the use of synthetic processing (Bocca, 1961; Matzker, 1959; Walsh and Goodman, 1955). A second approach is to administer more than the required 
amount of information, demanding that the patient separate and integrate phonemic stimuli into mearingful and nonmeaningful units (Calearo and Lazzaroni, 1957). The third approach is to present all the information necessary to analyze a message, but to present it in a complicated or unusual manner (Bocca, 1961; Katz, 1962). A fourth method is to combine two or more of the above procedures in order to obtain an even more demanding task.

The Staggered Spondaic Word Test (SSW) was devised to deal with the problem of assessing the central auditory pathways (Katz, 1962). The SSW Test is similar to Bocca's technique of switching the signal periodically from ear to ear. However, this test goes beyond Bocca's original demand by requiring the patient to attend first to one side, then to both sides simultaneously, and finally to the second side, with different information presented to each ear. The temporal sequencing of this dichotic listening presentation is schematically illustrated in Figure'l.

The development of the Staggered Spondaic Word Test took into consideration the test-retest reliability of the speech stimuli used. Spondaic words ${ }^{7}$ were chosen for this test for two reasons: first, they satisfied the test requirement of separate and overlapping units; and secondly, they offered a reliable relationship between the speech

7 Spondaic words, or "spondees" are two-syllable words with equal stress on each syllable (Wood, 1971). 


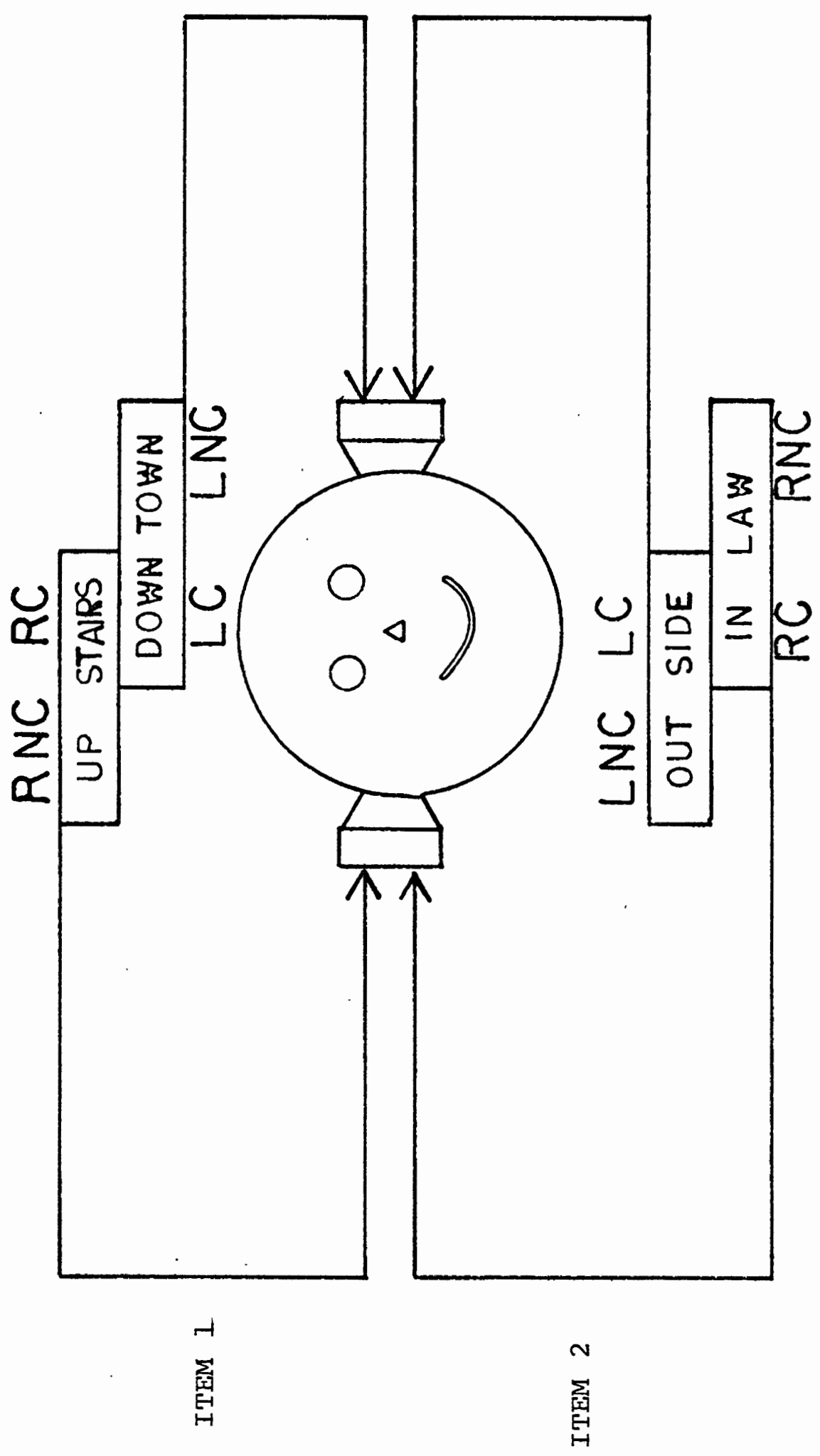

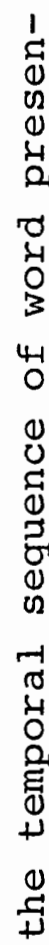

年 䓵 $+0$

$+9$

(1) त्

$+0$

$3 \stackrel{0}{1}$

U 1

U

出 4

$4-1$

(1)

당

है

لَّ 
reception threshold and the pure tone thresholds in the speech frequencies (Katz, 1962). Further, this relationship is essentially unaltered when auditory sensitivity is reduced and proves to be a highly stable speech stimuli (Brunt, 1972).

Thus, Katz has devised a test which is not only sensitive to central auditory disorders but one which is free of contamination due to peripheral hearing loss. In addition, it requires little sophistication or training on the part of the patient and is applicable to a wide range of patients regardless of age, intelligence, and education (Brunt, 1972).

The Staggered Spondaic Word Test has been proven to be a highly sensitive instrument in the evaluation of central auditory lesions (Balas, 1971; Jerger and Jerger, 1975; Katz, 1963; Katz, 1968). In a study presented by Jerger and Jerger (1975) a comparison was made between the Staggered Spondaic Word Test, the Synthetic Sentence Identification Test (SSI), the PBPI function, and a filtered speech test were administered to patients with confirmed lesions of the central auditory nervous system. These researchers concluded that the SSW test is an unusually sensitive tool in the evaluation of central auditory nervous system disorders. They go on to say that the combination of the SSW test and the SSI test offers a highly effective tool for 
differentiating and diagnosing brain stem and temporal lobe lesions.

The use of the SSW test with learning disabled children has been well documented (Katz, 1972; Stubblefield and Young, 1975; Willeford, 1976; Young and Tracy, 1977). Katz (1972) reported data on one thousand children demonstrating various degrees of learning disability who were seen at the Menorah Medical Center. Each child was given an SSW test in conjunction with a complete audiologic test battery. Learning disabled children who failed the SSW test displayed three test patterns: (I) the unilateral problem suggesting a severe dysfunction in auditory processing; (2) an inattention pattern; and (3) a unilateral difficulty processing wordsin the competing condition (i.e., the "A" pattern discussed by Katz). This response was demonstrated by both children and young adults with severe reading and spelling problems.

Little research has been reported with respect to dyslexic subjects' performance on the SSW test. Katz (1972) presents test results of two cases of reading retardation as being typical of the "A" pattern. Test performance for these subjects is entirely normal for the right-ear first items. However, there are a large number of errors on the left-ear first test items; these errors are only in the left competing condition. EEG test results of these patients suggests that the defective hemisphere is the contralateral 
hemisphere, suggesting a dysfunction posterior to the primary auditory reception area (temporo-occipital area).

\section{PURPOSE}

The term "dyslexia" is a functional word used to describe a myriad of associative and integrative disabilities resulting from both physiologic and environmental factors. Research investigating inadequate reading development has focused on the relationship between sensory and perceptual dysfunctions and the reading disability (Klasen, 1972). Although this research approach has yielded little conclusive evidence of specific etiologic factors, strong support for a genetic involvement has evolved. While studies have repeatedly reported case history and questionnaire information which suggest a familial lineage for dyslexia, none have reported formal or standardized test data which would empirically support their position. This research gap is particularly significant in view of the tendency of many researchers to consider dyslexia in terms of its relation to neurological correlates (Klasen, 1972).

The Staggered Spondaic Word test is an auditory test which has been demonstrated to be differentially sensitive to various learning disabled children and to individuals with central nervous system dysfunctions. Dyslexic children appear to perform uniquely on this test, revealing an inability to integrate competing stimuli when the messages 
are temporally introduced to the left ear slightly ahead of their arrival to the right ear. Katz's (1972) findings are consistent with previous research citing an inability to perform cross-modal integrative tasks and an inability to demonstrate normal responses on dichotic competing message listening tasks by dyslexics (Blank and Bridger, 1966; Johnson, 1972; Satz, 1965; Silver and Hagen, 1960). It should be noted that while the SSw test is not diagnostically definitive of central pathology nor conclusive in the discrete localization of site of lesion, an abnormal performance on this test is indicative of inadequate central auditory processing.

A study of the familial lineage of dyslexia, then, could be approached by comparing the staggered spondaic Word test performance scores through several generations. Stated differently, the question may be asked whether the Staggered Spondaic Word test performance scores of reading delayed children and those of their natural parents will show similar patterns.

\section{NULL HYPOTHESIS}

No significant relationship is predicted between the ssw test scores of dyslexic children and the scores of either of the natural parents. 


\section{CHAPTER III}

METHOD

\section{SUBJECTS}

Twenty-one dyslexic ${ }^{8}$ children, eight to thirteen years of age; were selected on the basis of teacher referrals in the Portland Public School system. School records were used to insure that subjects demonstrated reading performance 1.5 years or more below the average grade level, who sustained no severe peripheral visual impairments, demonstrated no gross or apparent neurological impairments, had no known past or present history of psychological disturbance, with no history of continual medical management, and whose hearing sensitivity was within normal limits. Further, subjects demonstrated average or better intelligence as measured on standardized test procedures conducted in the public school system, and showed average or better achievement in academic areas not directly related to reading, as determined by the classroom teacher. These children, their natural parents, and siblings (when possible) comprised the experimental population.

${ }^{8}$ Dyslexia is operationally defined as a disorder in children who, despite conventional classroom experience, fail to attain the language skills of reading, writing, and spelling commensurate with their intellectual abilities. 


\section{PROCEDURE}

Case history information was obtained from each subject. Questions solicited medical history, past and present hearing history, and educational history from each subject.

All testing was performed in an acoustic suite. Only the ear phones, a subject response button, an attached talkback microphone, and two permanently attached sound field speakers were in the testing suite with the subject during the test presentation. The remainder of the experimental instrumentation was located in the adjacent control room.

Children were given air conduction pure tone threshold tests utilizing a standard test procedure (Carhart and Jerger, 1959). Each adult subject was given a complete audiologic assessment, to include pure tone air conducted and bone conducted threshold testing, speech reception threshold testing, the determination of a comfortable and uncomfortable listening level, and speech discrimination testing utilizing a Campbell fifty-word speech list administered at the established comfortable listening level. In the event a significant difference in thresholds obtained between the two ears (40-50 dB HL), a comfortable listening level was determined for the poorer ear utilizing contralateral masking. In addition, any subject demonstrating speech discrimination poorer than 80 percent was eliminated from this study. 
Each subject was administered the Peabody Individual Achievement Test: Reading Comprehension and Reading recognition, utilizing test methods established by the authors of this test. Test results were analyzed in accordance with the normative data accompanying the test.

Prior to the administration of the tape-recorded Staggered Spondaic Word test, live-voice instructions were given to each subject by the examiner at a $50 \mathrm{~dB}$ sensation level transduced through talk-over microphones located in the control room and terminating in standard clinical earphones positioned on the subject. Instructions were outlined as follows (Katz, 1962):

You are going to hear some words which will be presented to one or both of your ears. The words will be presented in small groups. Just as soon as a group of words is completed, I would like you to repeat them all back to me. Take a guess if you are not quite sure of a word. Before each item you will hear the phrase, "Are you ready?" Please do not repeat this phrase, only the group of words that follow it.

A series of four trial test items loatmeal-flashlight; northwest-stairway; cowboy-whitebread; airplane-wetpaint) was given to the subject by the examiner until a success criterion of 100 percent was achieved.

The Staggered Spondaic Word test, list EC, was then administered to each subject at a $50 \mathrm{~dB}$ SL from a prerecorded test tape transcribed through a dual channel reelto-reel tape deck terminating in standard clinical earphones positioned on the subject. The tape was played with no 
interruption in presentation until all forty items were administered.

All subject responses were transduced through a talkback microphone positioned six inches from the subject's mouth. Responses were continually monitored by the examiner, and were recorded on a test answer form. In addition, all subject responses were tape-recorded onto a dual channel. cassette tape deck. Questionable responses were played. back to three graduate students in Speech and Hearing Science who made a final determination.

Test responses were scored according to instructions presented by Katz (1978). Performance scores were analyzed according to normative data established by Katz (1962, 1978, 1978a).

INSTRUMENTATION

The prerecorded Staggered Spondaic Word test tape, list EC, was transcribed through a dual channel reel-to-reel tape deck (Sony, Model TC 377). This output was fed to a dual channel clinical audiometer (MAICO, Model 24B). The output from the audiometer was patched from the control room into the examination room, terminating in standard audiologic earphones (Telephonics, Model TDH 39) mounted in MX 4l/AR cushions. The subject's verbal responses were transduced by a talk-back microphone and patched through the examination room and into the audiometer talk-back 
input. The subject's responses were monitored by the examiner through a second set of clinical earphones (Telephonics, Model TDH 39) mounted in MX 4I/AR cushions. Subject responses were recorded on a dual channel cassette tape deck (Technicks, Model $263 \mathrm{AU}$ ), patched from the talk-back system of the audiometer. All testing was conducted in a double wall, double room acoustic suite (Industrial Acoustics Corporation, Model 1403). A block diagram illustrating this instrumentation is presented in Figure 2.

\section{DATA}

Corrected SSW test scores constitute the data to be analyzed in this experiment. Subjects were divided into four discrete groups: (1) dyslexic children; (2) normal reading children; (3) affected parents, and (4) non-affected parents. SSW test scores were analyzed statistically utilizing the student's t-Test (Thompson, 1965). Group mean test scores were computed for standard deviations and pattern analysis. Test data were analyzed to answer the following questions:

1. Do the ssw test scores for the dyslexic subjects show a poor performance in any test condition?

2. Do one or both parents exhibit similarly degraded test scores in the same condition?

3. Do degraded test scores appear more frequently among male or female subjects? 


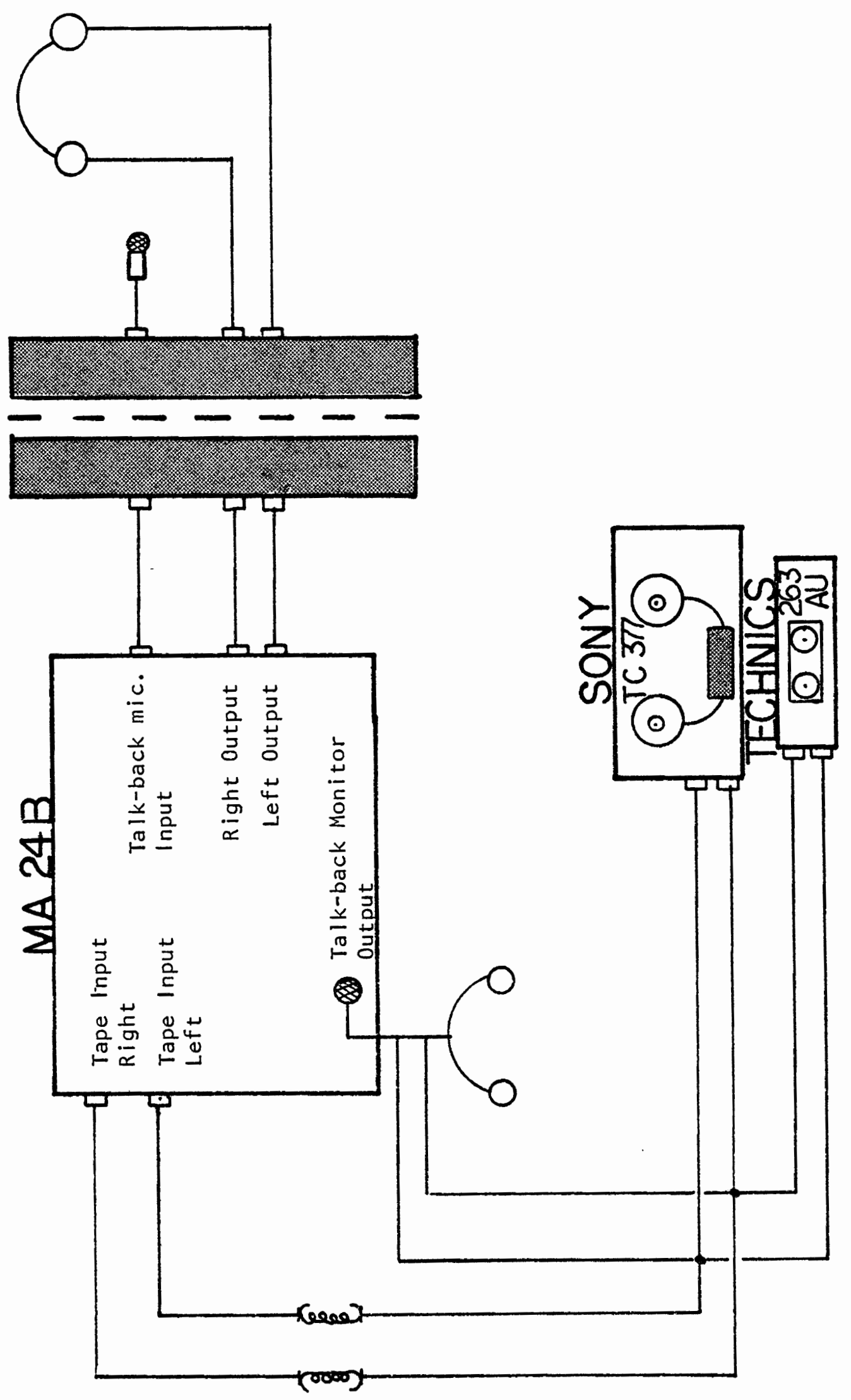

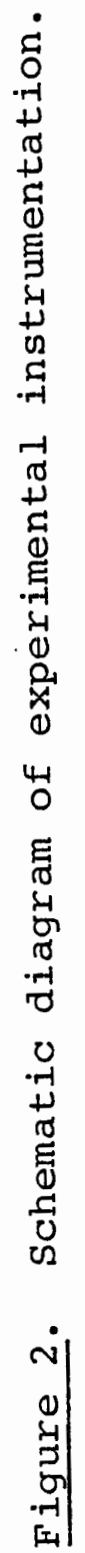


4. Do normal reading children from these families demonstrate an abnormal performance on the SSW test? 


\section{CHAPTER IV}

\section{RESULTS}

The purpose of this study was to investigate the possibility of a familial lineage for dyslexia by analyzing the auditory processing characteristics of dyslexic children and their parents. The staggered Spondaic Word (SSW) test was used in an effort to determine whether a unique test performance indicative of a central auditory processing deficit, would be manifested by reading-delayed children and one or both natural parents. Twenty-one dyslexic children (sixteen males and five females) between the ages of eight and thirteen years were administered the SSW test in addition to a routine audiologic assessment. All subjects had normal peripheral hearing sensitivity and speech discrimination. The experimental sample was 1.85 mean years delayed in reading and represented sixteen famlies. The SSW test was also given to the parents and normal reading siblings in an effort to learn more about auditory processing characteristics of all family members. Experimental listening conditions which appeared to fall consistently below the range of normal limits provided a basis for intergroup comparisons in order to determine statistical significance. 
A visual inspection of the tabulated data presented in Table I suggests that the mean scores in the left competing test condition were consistently depressed for the dyslexic subjects. These results support Katz's (1972) findings that dyslexic listeners exhibit degraded performance on the SSW test. Raw test scores of reading-delayed children in this study (see Appendix A) revealed that all subjects obtained abnormal ${ }^{9}$ test scores in one or more competing and non-competing test conditions.

\section{TABLE I}

MEAN PERCENTAGE 'SSW TEST SCORES FOR ALL SUBJECTS IISTED ACCORDING TO LISTENING CONDITION

\begin{tabular}{|c|c|c|c|c|c|}
\hline Subjects & Mean & $\begin{array}{c}\text { Right } \\
\text { N-C }\end{array}$ & $\begin{array}{c}\text { Right } \\
\mathrm{C}\end{array}$ & $\begin{array}{c}\text { Left } \\
\mathrm{C} \\
\end{array}$ & $\begin{array}{l}\text { Left } \\
\bar{j}-\mathrm{C}\end{array}$ \\
\hline $\begin{array}{l}\text { Dyslexic } \\
\text { Children } \\
(\mathrm{N}=21)\end{array}$ & $\overline{\mathrm{X}}$ & 92.76 & 82.74 & 73.86 & 91.83 \\
\hline $\begin{array}{l}\text { Normal } \\
\text { Reading } \\
\text { Siblings } \\
(\mathrm{N}=5)\end{array}$ & $\overline{\mathrm{x}}$ & 100.00 & 96.00 & 85.50 & 98.00 \\
\hline $\begin{array}{l}\text { Affected } \\
\text { Parents } \\
(\mathrm{N}=13)\end{array}$ & $\overline{\mathrm{x}}$ & 96.54 & 88.36 & 80.36 & 98.00 \\
\hline $\begin{array}{l}\text { Non- } \\
\text { Affected } \\
\text { Parents } \\
(N=18)\end{array}$ & $\overline{\mathrm{X}}$ & 99.50 & 98.80 & 96.60 & 99.30 \\
\hline
\end{tabular}

$9^{9}$ For purposes of this study, 91 percent constituted the lower end of the normal range. 
In addition, Table I presents the mean test scores of the dyslexic children, parents, and siblings in each experimental test condition: right non-competing, right competing, left competing, and left non-competing. The raw test scores of the parents (see Appendices $B$ and $C$ ) fell into two discrete groups: non-affected, with normal test scores in all test conditions, and affected parents who demonstrated a degraded score in one or more test conditions. A visual inspection of this table clearly illustrates the depressed scores in the left competing mode for the dyslexic children and the affected parents, which represented 42 percent of the total parent group.

The differences between the mean percentage SSW test scores of dyslexic children and affected parents were analyzed statistically utilizing the student's t-Test (Thompson, 1965). Mean test scores, standard deviations, and t-values are presented in Table II. This analysis revealed no significant difference between the test scores of the dyslexic children and affected parents in the right noncompeting, right competing, or left competing listening conditions, suggesting similar SSW test performances exist for the dyslexic subjects and affected parents in most listening conditions. Differences between the test scores of dyslexics and affected parents were significantly different only in the left non-competing test condition. 
TABLE II

MEAN PERCENTAGE SSW SCORES, STANDARD DEVIATIONS, AND t-VALUES FOR DYSLEXIC CHILDREN AND AFFECTED

PARENTS LISTED ACCORDING TO LISTENING CONDITION

\begin{tabular}{|c|c|c|c|c|}
\hline $\begin{array}{l}\text { Listening } \\
\text { Condition } \\
\end{array}$ & Mean & $\begin{array}{c}\text { Dyslexic } \\
\text { Children } \\
(\mathrm{N}=21)\end{array}$ & $\begin{array}{c}\text { Affected } \\
\text { Parents } \\
(\mathrm{N}=12)\end{array}$ & t-Value \\
\hline $\begin{array}{l}\text { Right Non- } \\
\text { competing }\end{array}$ & $\begin{array}{c}\bar{X} \\
S \cdot D .\end{array}$ & $\begin{array}{r}92.76 \\
6.64\end{array}$ & $\begin{array}{r}96.80 \\
2.85\end{array}$ & 2.00 \\
\hline $\begin{array}{l}\text { Right } \\
\text { Competing }\end{array}$ & $\begin{array}{l}\bar{X} \\
S \cdot D\end{array}$ & $\begin{array}{l}82.74 \\
13.48\end{array}$ & $\begin{array}{l}88.36 \\
13.06\end{array}$ & 1.05 \\
\hline $\begin{array}{l}\text { Left } \\
\text { Competing }\end{array}$ & $\begin{array}{c}\overline{\mathrm{X}} \\
\text { S.D. }\end{array}$ & $\begin{array}{l}73.86 \\
12.85\end{array}$ & $\begin{array}{l}80.36 \\
14.47\end{array}$ & 1.23 \\
\hline $\begin{array}{l}\text { Left Non- } \\
\text { competing }\end{array}$ & $\begin{array}{c}\bar{X} \\
\text { S.D. }\end{array}$ & $\begin{array}{r}91.83 \\
5.91\end{array}$ & $\begin{array}{r}98.00 \\
2.80\end{array}$ & $3.54^{\mathrm{a}}$ \\
\hline
\end{tabular}

$a_{A} t$-value of $3.640(d f=32)$ is required for significance at the 0.001 level of confidence.

A statistical analysis of the differences between mean percentage SSW test scores of dyslexic children and nonaffected parents (Table III) revealed differences which were significant beyond the 0.001 level of confidence in all listening conditions. These statistical data suggest dissimilar test scores for dyslexic children and non-affected parents, supporting the closer relationship between the SSW test performances of dyslexic children and their affected parents than between dyslexic children and non-affected parents.

In order to analyze the relationship between the test scores of the dyslexic children with those of the individually affected parents, individual family test scores were 
TABLE III
MEAN PERCENTAGE SSW SCORES, STANDARD DEVIATIONS, AND t-VALUES FOR DYSLEXIC CHILDREN AND NON-AFFECTED PARENTS LISTED ACCORDING TO LISTENING CONDITION

\begin{tabular}{lcccc}
\hline \hline $\begin{array}{l}\text { Listening } \\
\text { Condition }\end{array}$ & Mean & $\begin{array}{c}\text { Dyslexic } \\
\text { Children } \\
(\mathrm{N}=21)\end{array}$ & $\begin{array}{c}\text { Non-Affected } \\
\text { Parents } \\
(\mathrm{N}=12)\end{array}$ & t-Value \\
\hline $\begin{array}{l}\text { Right Non- } \\
\text { Competing }\end{array}$ & $\overline{\mathrm{X}}$ & 92.76 & 99.50 & $4.34^{\mathrm{a}}$ \\
& S.D. & 6.64 & 1.32 & \\
Right & $\overline{\mathrm{X}}$ & 82.74 & 98.80 & $5.02^{\mathrm{a}}$ \\
Competing & S.D. & 13.48 & 2.19 & \\
Left & $\overline{\mathrm{X}}$ & 73.86 & 96.60 & $7.34^{\mathrm{a}}$ \\
Competing & S.D. & 12.85 & 3.05 & \\
Left Non- & $\overline{\mathrm{X}}$ & 91.83 & 99.30 & $5.22^{\mathrm{a}}$ \\
Competing & S.D. & 5.91 & 1.46 & \\
\hline
\end{tabular}

$a_{A} t$-value of $3.551 \quad(d f=37)$ is required for significance at the 0.001 level of confidence.

compared. For purposes of this analysis only test scores in the left competing mode were utilized. This comparison was calculated by subtracting the test score of the dyslexic child in the left competing condition from the score of the affected parent (A) and from the score of the non-affected parent (N).. An examination of the differences between children and their affected and non-affected parents (see Appendix E) suggests a closer relationship between the test scores of the child and affected parent than with those of the non-affected parent. The mean test differences between groups $A$ and $N$ were analyzed statistically and found to be significant at the 0.02 level of confidence. 
Visual inspection of the mean percentage SSW test error responses by affected and non-affected parents revealed inordinate differences in the left competing condition (see Figure 3). From this histogram, it becomes clear that the performance patterns between parents tended to differ most dramatically in the left competing mode.

A statistical analysis of the differences between the mean percentage test scores for affected and non-affected parents is presented in Table IV. The differences between the mean test scores for both groups of subjects were significant in the right non-competing, right competing, and left competing test conditions at the 0.001 level of confidence. Only the left non-competing listening condition failed to show significant differences at this level.

This study revealed differences in the raw test scores of dyslexic children and those of their normal reading siblings (see Appendix D). Figure 4 shows the mean test errors of both groups and illustrates the greater percentage of errors in all competing conditions for the dyslexic children. The difference is most dramatic in the left competing mode.

A statistical analysis of the differences between the mean percentage test scores for the dyslexic children and their normal reading siblings (see Table V) revealed differences significant at the 0.02 level of confidence in all listening conditions except the left competing which was 
Affected Parents

Non-Affected Parents
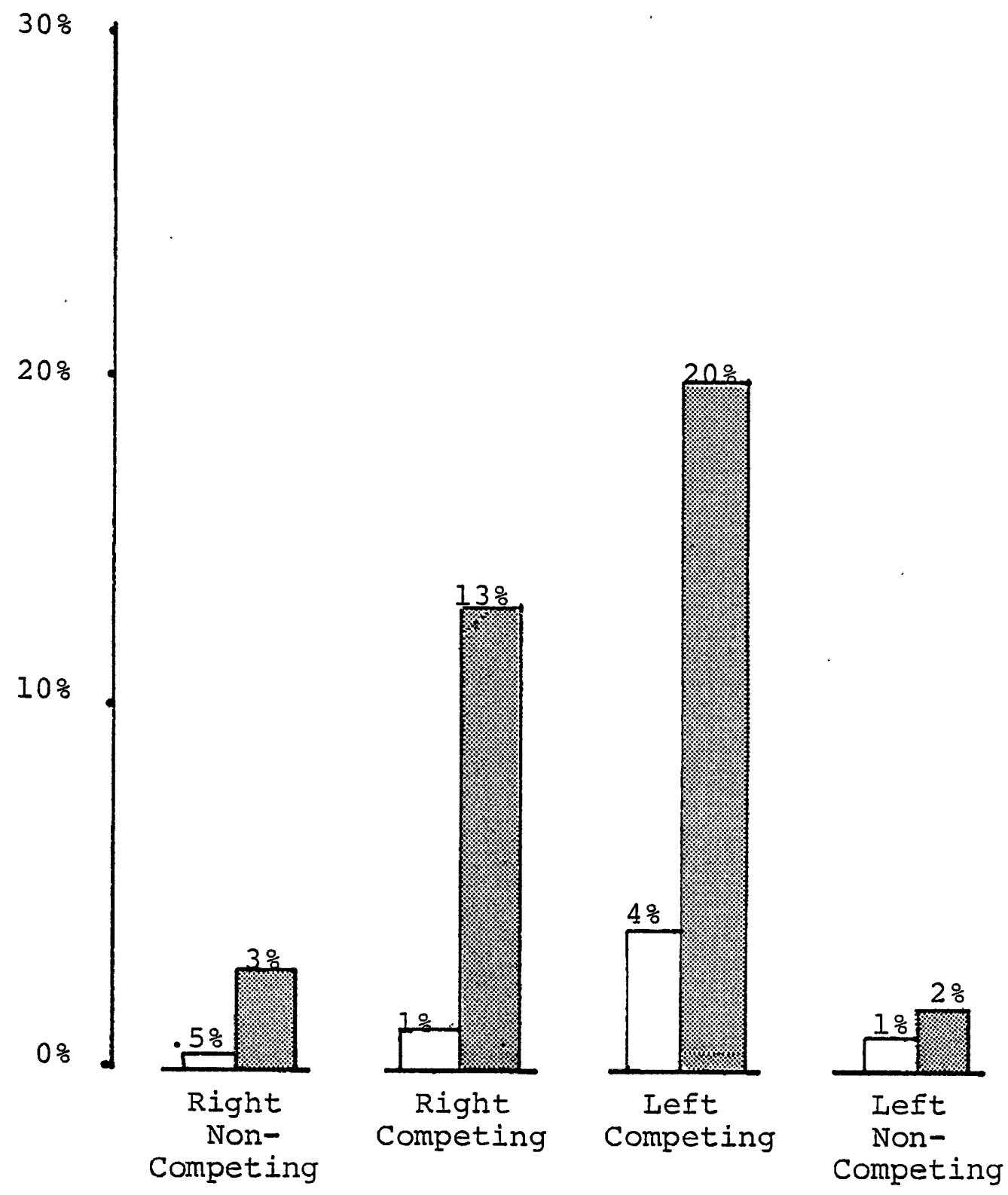

Figure 3. Illustrates mean SSW test errors for affected and non-affected parents as a function of the listening condition. 
Dyslexic Children

Normal Reading

Children
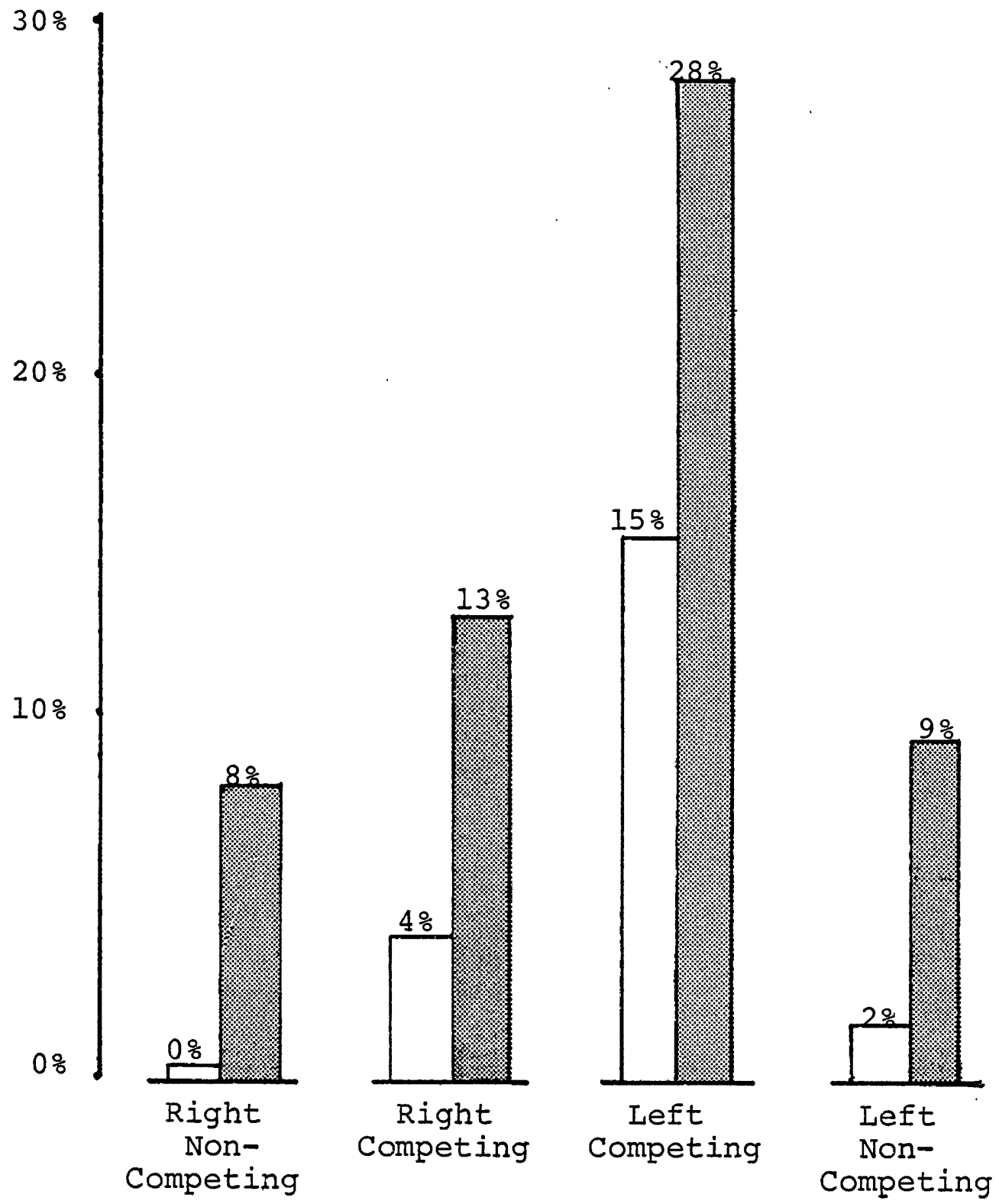

Figure 4. Illustrates mean SSW test errors of dyslexic children and their normal reading siblings as a function of the listening condition. 
TABLE IV

MEAN PERCENTAGE SSW SCORES, STANDARD DEVIATIONS, AND t-VALUES FOR AFFECTED AND NON-AFFECTED PARENTS LISTED ACCORDING TO LISTENING CONDITION

\begin{tabular}{lcccc}
\hline Listening & Mean & $\begin{array}{c}\text { Affected } \\
\text { Parents } \\
(\mathrm{N}=13)\end{array}$ & $\begin{array}{c}\text { Non-affected } \\
\text { Parents } \\
(\mathrm{N}=18)\end{array}$ & t-Value \\
\hline $\begin{array}{l}\text { Right Non- } \\
\text { Competing }\end{array}$ & $\overline{\mathrm{X}}$ & 96.54 & 99.50 & $4.07^{\mathrm{a}}$ \\
Right & $\overline{\mathrm{X}}$ & 2.80 & 1.32 & \\
Competing & S.D. & 88.36 & 98.80 & $3.52^{\mathrm{b}}$ \\
Left & $\overline{\mathrm{X}}$ & 13.06 & 2.19 & \\
Competing & S.D. & 80.36 & 96.60 & $4.70^{\mathrm{a}}$ \\
Left Non- & $\overline{\mathrm{X}}$ & 14.47 & 3.05 & \\
Competing & S.D. & 98.00 & 99.30 & 1.55 \\
\hline
\end{tabular}

$a_{A} t$-value of $3.659(d f=29)$ is required for significance at the 0.001 level of confidence.

$b_{A} t$-value of 2.756 is required for significance at the 0.01 level of confidence.

significant at the 0.1 level. Among normal reading children maturational performance limitations are most conspicuous in the left competing condition; consequently, the difference between performance scores of dyslexic and non-dyslexic children are least significant in this condition, an artifact that is supported by the present investigation.

Figure 5 illustrates the degraded performance of dyslexic children and affected parents in both the right and left competing test conditions as compared with the non-affected family members. The poorer performance of the affected parents in this sample is readily apparent even when compared with that of their normal reading children. 
Dyslexic Children

$\square$ Normal Reading Siblings
- Affected Parents

Non-Affected Parents

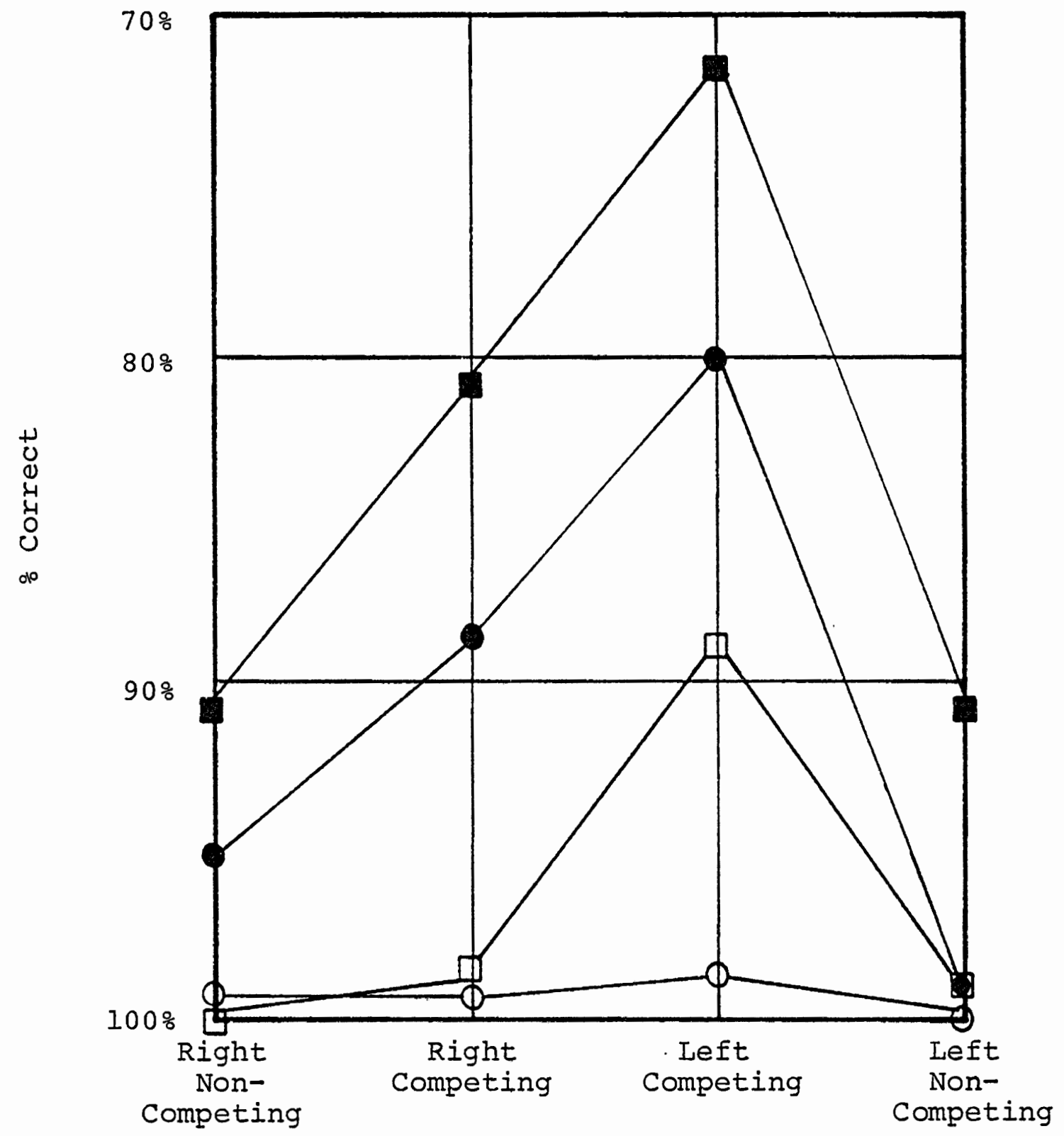

Figure 5. Comparison of mean percent correct responses as a function of listening condition for all experimental groups. 
TABLE V

MEAN PERCENTAGE SSW SCORES, STANDARD DEVIATIONS, AND $t$-VALUES FOR DYSLEXIC CHILDREN AND NORMAL READING SIBLINGS LISTED ACCORDING TO LISTENING CONDITION

\begin{tabular}{lcccc}
\hline \hline $\begin{array}{l}\text { Listening } \\
\text { Condition }\end{array}$ & Mean & $\begin{array}{c}\text { Dyslexic } \\
\text { Children } \\
(\mathrm{N}=21)\end{array}$ & $\begin{array}{c}\text { Normal } \\
\text { Readers } \\
(\mathrm{N}-5)\end{array}$ & t-Values \\
\hline $\begin{array}{l}\text { Right Non- } \\
\text { Competing }\end{array}$ & $\overline{\mathrm{x}}$ & 92.76 & 100.00 & $2.43^{\mathrm{a}}$ \\
& S.D. & 6.64 & 0.00 & \\
Right & $\overline{\mathrm{x}}$ & 82.74 & 96.00 & $2.14^{\mathrm{b}}$ \\
Competing & S.D. & 13.48 & 4.54 & \\
Left & $\overline{\mathrm{x}}$ & 73.86 & 85.50 & $1.83^{\mathrm{C}}$ \\
Competing & S.D. & 12.85 & 12.30 & \\
Left Non- & $\overline{\mathrm{X}}$ & 91.83 & 98.00 & $2.25^{\mathrm{b}}$ \\
Competing & S.D. & 5.91 & 2.74 & \\
\hline
\end{tabular}

$a_{A} t$-value of $2.492(d f=24)$ is required for significance at the 0.02 level of confidence.

$b_{A} t$-value of 2.064 is required for significance at the 0.05 level of confidence.

$c_{A} t$-value of 1.711 is required for significance at the 0.1 level of confidence.

In view of the significantly degraded performance by dyslexic children and affected parents, the null hypothesis presented in Chapter II, stating that no significant relationship would be predicted between the SSW test scores of dyslexic children and the scores of their parents, must be rejected. If the relationship observed between dyslexia and impaired central auditory processing is tenable, then the present student appears to support a hereditary predisposition. 


\section{CHAPTER V}

\section{DISCUSSION}

Many reading-delayed children demonstrate an abnormal performance on phonemic tests which are sensitive to deficits in the central auditory pathways (Johnson, 1972; Katz, 1972; Willeford, 1976; Young and Tracy, 1977). The Staggered Spondaic Word (SSW) test is particularly sensitive to children with various learning disabilities, including dyslexia (Katz, 1972; Young and Tracy, 1977).

Compelling evidence has been offered supporting a genetic basis for dyslexia (Critchley, 1970; Hallgren, 1950; Satz, 1970; Mykelbust and Johnson, 1962; Orton, 1935). To date, however, standardized test data have not been reported to support this relationship. This paucity of empirical support for a genetic precursor to dyslexia is conspicuous when one considers the tendency of many researchers to view dyslexia in terms of neurological correlates (Klasen, 1972). The present study investigated the possibility of genetic involvement in dyslexia by analyzing dichotic listening performance scores of dyslexic chilaren and their parents. In the present study the SSW test was used to assess certain central auditory processing deficits in a sample of dyslexic children and their families. It was reasoned that 
if central auditory processing deficits are of genetic origin they can be transmitted from one generation to the next, and evidence of this transmission might be demonstrated behaviorally by poor performance scores on tests sensitive to central auditory dysfunction among parents of reading-delayed children.

While the SSW test performances among children and parents were not invariant, there was an inordinantly high incidence of affected parents found within this sample. The normative SSW test data for adults (Katz, 1972) indicate that degraded performance scores (90 percent or less) are quite rare. Yet 42 percent of the parents of dyslexic children demonstrated this deficiency. It seems plausible that while a genetic factor may be responsible for a degraded test performance among dyslexic children, this factor may not necessarily surface in each generation. Moreover, dyslexia is at best a vaguely defined syndrome, wherein the definition concentrates on the effects and not the causes; it also seems possible that there are different forms of this problem, some of which may have a hereditary basis and some which do not. In the present study dyslexic children were selected conventionally on the basis of poor reading performance with attempts made to rule out concomitant conditions which might contribute to poor reading skills. However, the operational definition employed in sample selection may not be entirely valid. 
The degraded performance by dyslexic children and affected parents depicted in Figure 6 appears to be similar to the pattern exhibited by chronologically younger children who are neurologically immature. For example, the mean sSW score for dyslexic children in this study, mean age 9.9 years ( 85.30 percent) corresponds to a normative value of 86.60 percent for the average six-year-old (Katz, 1972). However, the high incidence of abnormal dichotic listening performance among parents of dyslexic children would suggest that neurological maturity is still incomplete in adulthood. This would tend to support the concept of an hereditary insufficiency that persists into adulthood despite the fact that the parents acquired reading skills. For example, in this sample all affected parents completed secondary education, with five achieving university education or even advanced degrees. Thus, the maturational hypothesis (Satz and Sparrow, 1970; Satz, Reardin and Ross, 1971) suggesting that dyslexia is the result of immature neurological development which is resolved with adulthood, is inconsistent with the results of the present study.

Since there is a high probability that one or both parents of dyslexic children will yield an SSW test score of 90 percent or less in the left competing listening condition, the SSW test may be useful in detecting high-risk children. That is, an SSW test score of the parents may provide important predictive information concerning the 
Dyslexic Children

- Affected Parents

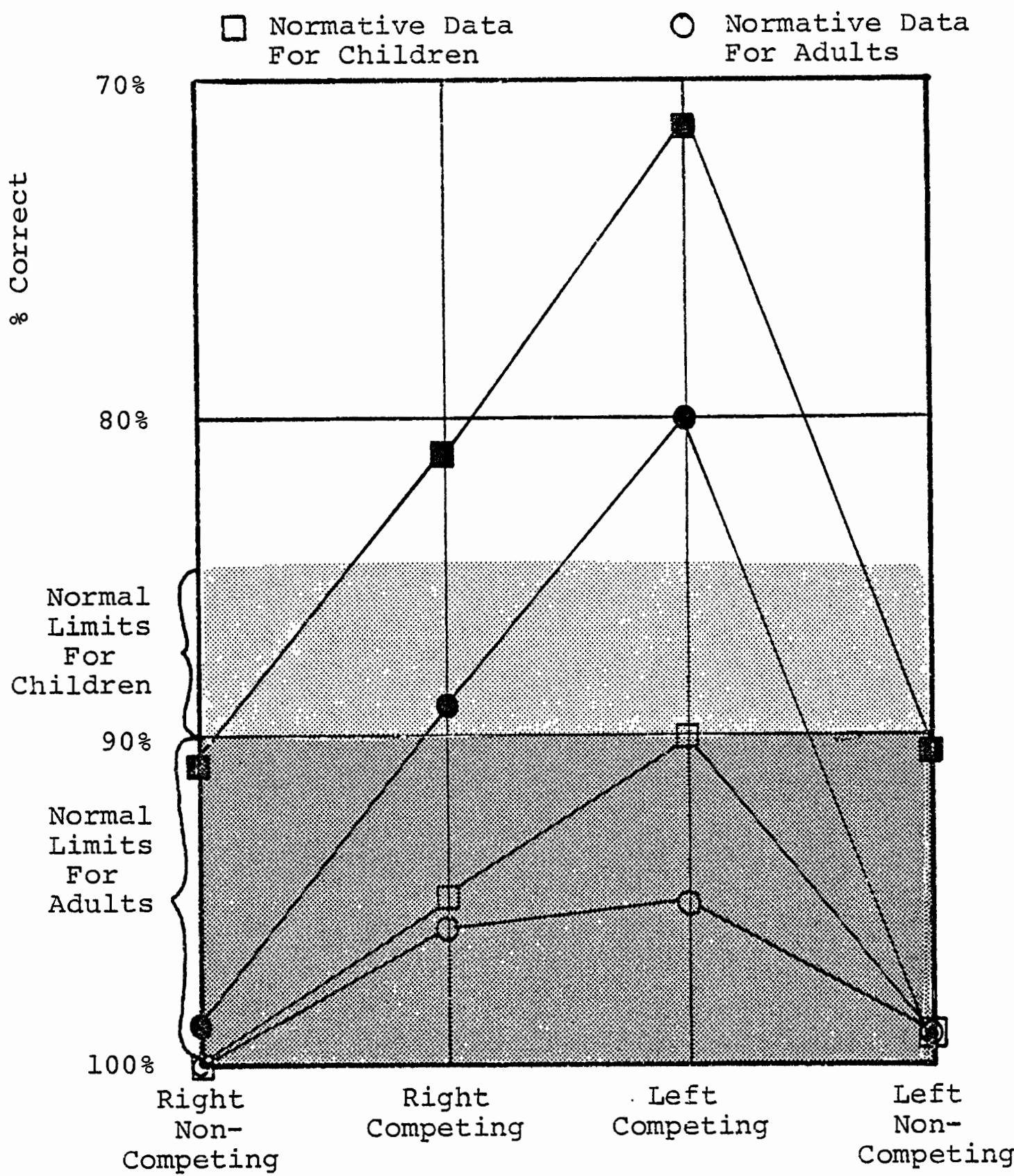

Figure 6. Comparison of mean percent correct responses as a function of listening condition for dysiexic children and affected parents with mean normative data for children and adults. 
potential learning problems of their children. While the presence of a normal test score for both parents should not be used to eliminate the possibility of an auditory processing deficit in their children, an abnormal score for either parent indicates a high probability that their child will also sustain a central auditory processing deficit, the cause of which may effectively interfere with the acquisition of reading skills. A large population study of parents of dyslexic children appears warranted in order to provide probability data useful in establishing risk criteria for dyslexia.

SSW test scores of dyslexic children in this investigation may indicate the presence of a central auditory processing deficit which yields degraded performances in a dichotic competing listening condition. This suggests that reading-delayed children experience inordinate difficulty processing speech stimuli in the presence of message competition. The test results from this study imply that classroom noise involving propositional message competition, such as other children talking during receptive language tasks, would clearly degrade the performance of dyslexic children. This may extend to non-propositional noise as well and consideration should be given to an investigation of this parameter since the intrusion of noise in special education and regular classrooms is a common problem. 
The development of management strategies for dyslexic children is dependent on an understanding of the nature of the processing deficits present in the child. Katz (1978) reported that a significant number of errors in the left competing test condition on the SSW test may be consistent with a deficit in a "non-auditory reception area" of the brain, such as the parietal or occipital lobes. This suggests that there may be other processing deficits as well, such as visual processing, since the occipital portion of the brain has been associated with higher order visual activities (Gazzangia and Sperry, 1967). That is, the central auditory processing deficit identified in this investigation may be the result of a larger, more basic disturbance which could involve other sensory areas.

A number of the errors noted in this study consisted of complete or partial reversals: for example, the stimulus "white walls--dog house" might be repeated as "dog house--white walls" (a complete reversal) or as "dog house-dog walls" (a partial reversal). Katz (1978) postulated that a large number of reversals are consistent with involvements of the fronto-parietal region of the brain.

Two interesting but unquantified differences were observed between normal performance and the abnormal performance of dyslexic subjects and affected parents: response latency and a tendency for rehearsal. The affected listeners, once they were instructed to delay responding until 
both spondees had been presented, tended to delay responding for a brief interval, during which they appeared to echoically reconstruct each stimulus. This was visible in many cases and observed as lip movements. Rehearsal behavior is common among preschool children acquiring language (McCarthy, 1930) and was not observed among normal siblings or non-affected parents in this sample. These behavior patterns appear to support a neurological immaturity theory for dyslexia.

\section{CONCLUSION}

The SSW test results obtained in the present investidation suggest the presence of a central auditory processing deficit in dyslexic children and one or both affected parents. Those data tend to support a genetic predisposition for dyslexia. In addition, test results of both the dyslexic children and affected parents are consistent with the hypothesis that dyslexia is the result of neurological immaturity which remains unresolved with adulthood. This support for an organic involvement in dyslexic children suggests a need to carefully redefine "dyslexia" in terms of possible genetic and neurological correlates, thereby distinguishing this form from other types of reading delay. Finally, the establishment of effective management strategies for dyslexic children cannot be developed until the 
sensory processing deficits underlying dyslexia are better understood.

\section{IMPLICATIONS FOR FURTHER RESEARCH}

The present investigation suggests several areas for further investigation:

1. Utilization of the SSW test with a population of dyslexic adults and their children to further support genetic involvement in dyslexia.

2. A large population study utilizing only male dyslexic children and their families in an effort to establish possible sex-linked characteristics in the transmission of dyslexia.

3. A large population study of dyslexic children and their parents utilizing the SSW test in an effort to establish risk criteria for the early identification of dyslexic children.

4. A study designed to measure the latency of responses of dyslexic children and affected family members on the SSW test in an effort to further refine the neurological involvement in dyslexia.

5. A study of other sensory processing deficits, including visual-perceptual, present in dyslexic children and their parents. 
6. Further research on the effects of propositional message competition in the environment during management sessions with dyslexic children.

7. A study of the effectiveness of various methods for reducing dichotic message competition in the management of dyslexic children.

8. A questionnaire study designed to elicit methods utilized by affected parents in learning to read, including coping and training mechanisms which facilitated the development of the reading skill. 
A SELECTED BILBLIOGRAPHY 


\section{A SELECTED BIBLIOGRAPHY}

Bakker, D. "Ieft-Right Differences in Auditory Perception of Verbal and Nonverbal Material by Children." Quarterly Journal of Experimental Psychology 19 (1967): 334-36.

Balas, R. "SSW Test: Support." Annals of Otology, Rhinology and Laryngology 80 (1971):132-34.

Belmont, L., and Birch, H. "Lateral Dominance and RightLeft Awareness in Normal Children." Child Development $34(1963): 257-70$.

"Lateral Dominance, Lateral Awareness and Reading Disability." Child' Development 36 (1965):59-71.

Bettman, J. "Cerebral Dominance in Developmental Dyslexia: Role of the Opthalmologist." Archives of Opthalmology 78 (1967):722-29.

Birch, H., and Belmont, I. "Auditory-Visual Integration in Normal and Retarded Readers." American Journal of

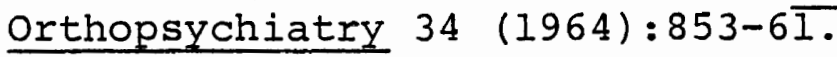

Blank, M., and Bridger, W. "Deficiencies in Verbal Labeling in Retarded Readers." American Journal of Orthopsychiatry 36 (1966):840-47.

Bocca, E.; Calearo, C; and Cassinari, V. "Testing 'Cortical' Hearing in Temporal Lobe Tumors." Acta Otolaryngology 45 (1955):289-94.

Bocca, E. "Factors Influencing Binaural Integration of Periodically Switched Messages." Acta Otolaryngology $53(1961): 142-44$.

Bocca, E., and Calearo, D. In Modern Developments in Audiology. Edited by J. Jerger. New York: Academic Press, 1963.

Brunt, M. "The Staggered Spondaic Word Test." In Handbook of Clinical Audiology. Edited by J. Katz. Baltimore: William and Wilkins Co., 1972 . 
Bryden, M. "Laterality Effects in Dichotic Listening: Relations with Handedness and Reading Ability in Children." Neuropsychologica 8 (1970):443-50.

Butters, N., and Brody, B. "The Role of the Left Parietal Lobe in the Mediation of Inta- and Cross-Modal Associations." Cortex 4 (1968):328-43.

Calearo, C., and Lazzaroni, A. "Speech Intelligibility in Relation to the speed of the Message." Laryngoscope 67 (1957): 410-19.

Carhart, R., and Jerger, J. "Preferred Method for Clinical Determination of Pure-Tone Threshold." JSHD 24 $(1959): 330-45$.

Critchley, M. The Dyslexic Child. London: William Hinemann Medical Books Limited, 1970.

Drew, A. "A Familial Congenital Word Blindness." Brain 79 $(1956): 440-60$.

Gazzangia, M., and Sperry, R. "Language after section of the Cerebral Commisures." Brain 90 (1967):131-48.

Geshwind, N. "Disconnection Syndrome in Animals and Man." Brain 88 (1965):237-94.

Gray, H. Anatomy, Descriptive and Surgical. Philadelphia: Running Press, 1974 .

Hallgren, B. "Specific Dyslexia--A Clinical and Genetic Study." Psychiatrica Neurologica Supplement 65 (1950) : 1- 287 .

Holroyd, R., and Reiss, R. "Central Auditory Disturbances in Dyslexic School Children." Journal of Special Education 2 (1968):209-215.

Jerger, J., and Jerger, S. "Clinical Validity of Central Auditory Tests." Journal of Scandanavian Audiology 4 (1975):147-63.

Johnson, D. "A Study of Dichotic Listening in Normal Children and Children with Verbal Learning Disabilities." Dissertation Abstracts International 32 (1972): $4352-53$.

Katz, J. "The Use of Staggered Spondaic Words for Assessing the Integrity of the Central Auditory System." Journal of Auditory Research 2 (1962):327-37. 
Katz, J.; Basil, R.; and Smith, J. "A Staggered Spondaic Word Test for Detecting Central Auditory Lesions." Annals of Otology, Rhinology and Laryngology 72 $(1963): 908-917$.

Katz, J. "The SSW Test: An Interim Report." JSHD 33 (1968) : 132-46.

Katz, J., and IIlmer, R. "Auditory Perception in Children with Learning Disabilities." In Handbook of Clinical Audiology. Edited by J. Katz. Baltimore: Williams and Wilkins Co., 1972 .

Katz, J. "Clinical Use of Central Auditory Tests." In Handbook of Clinical Audiology, 2nd ed. Edited by J. Katz. Baltimore: Williams and Wilkins Co., 1978.

- Portland State University, Portland, Oregon. Personal communication, 1978a.

Klasen, E. The Syndrome of Specific Dyslexia. Baltimore: University Park Press, 1972.

Lenneberg, E. Biological Foundations of Language. New York: Wiley, 1967 .

Manson, J. "Dyslexia: Definition, Diagnosis and Remediation." Australian Journal of Remedial Education 7 $(1975): 9-15$.

Masland, R. "Implications for Therapy." In Early Experiences and Visual Information Processing in Perceptual and Reading Disorders. Washington, D.C.: National Academy of Sciences, 1970 .

Matzker, J. "Two Methods for the Assessment of Central Auditory Functions in Cases of Brain Disease." Annals of Otology, Rhinology and Laryngology 68 (1959): 1185-97.

McCarthy, D. The Language Development of the Preschool Child. Minneapolis: University of Minnesota Press, 1930 .

Mercer, C.; Forgnone, C.; and Wolking, W. "Definitions of Learning Disabilities in the U.S." Journal of Learning Disabilities 9 (1976):376-86.

Merifield, D. "The Otolaryngologist and Learning Disabilities." Archives of Otolaryngology 91 (1970):470-73. 
Mykelbust, H., and Johnson, D. "Dyslexia in Children." Exceptional Children 29 (1962): 14-25.

Mulder, R., and Curtin, J. "Vocal Phonic Ability and Silent Reading Achievement: A First Report." Elementary School Journal 56 (1955): 121-23.

Oakland, T. "Auditory Discrimination and Socio-Economic Status as Correlates of Reading Ability." Journal of Learning Disabilities 2 (1969): 325-29.

Orton, s. Reading, Writing and Speech Problems in Children. London: Chapman Hall, 1937.

Rosenthal, J. "Recent Advances in the Neurophysiology of Some Specific Cognitive Functions." Academic Therapy $8(1973): 423-28$.

Satz, P. "Order of Report, Ear Assymetry and Handedness in Dichotic Listening." Cortex 1 (1965): 377-96.

Satz, P., and Sparrow, S. "Specific Developmental Dyslexia: A Theoretical Formulation." In Specific Reading Disability: Advances in Theory and Method. Edited by D. Bakker. Rotterdam: Rotterdam University Press, 1970 .

Satz, P.; Reardin, D.; and Ross, J. "An Evaluation of a Theory of Specific Developmental Dyslexia." Child Development 42 (1971): 2009-21.

Shepard, E. "Reading Efficiency of 809 Average School Children." American Journal of Ophthalmology 41 $(1956): 1029-39$.

Silver, A., and Hagen, R. "Specific Reading Disability: Delineation of the Syndrome and Relationship to Cerebral Dominance." Comprehensive Psychiatry 1 (1960): $126-34$.

Silver, I. "Familial Patterns in Children with Neurologically Based Learning Disabilities." Journal of Learning Disabilities 4 (1971): 349-58.

Spreen, 0. "Postscript: Review and Outlook." In Specific Reading Disability: Advances in Theory and Method. Edited by D. Bakker. Rotterdam: Rotterdam University Press, 1970 .

Stubblefield, J., and Young, E. "Central Auditory Dysfunction in Learning Disabled Children." Journal of Learning Disabilj.ties 8 (1975): 89-94. 
Studdert-Kennedy, M., and Shankweiler, D. "Hemispheric Specialization for Speech Perception." JASA 48 $(1970): 579-94$.

Thompson, R. Statistical Methods Useful in Medicine. Portland, Ore.: Department of Public Health and Preventive Medicine, 1965.

U.S. Department of Health, Education and Welfare. Report on Dyslexia and Related Reading Disorders. Washington, D.C.: Government Printing Office, 1969.

Walsh, T., and Goodman, A. "Speech Discrimination in Central Auditory Lesions." Iaryngoscope 65 (1955): 1-8.

Warrington, E.; James, M.; and Kinsbourne, K. "Drawing Disability in Relation to Laterality of Cerebral Lesion." Brain 89 (1966): 53-82.

White, C. "Dyslexia:. Is the Term of Value?" Acta Symbolica $4(1973): 6-28$.

Willeford, J. "Central Auditory Functions in Children with Learning Disabilities." Audiology Hearing Education $2(1976): 12-20$.

Wood, K. "Terminology and Nomenclature." In Handbook of Speech Pathology and Audiology. Edited by I. Travis. Englewood Cliffs, N.J.: Prentice-Hall, Inc., 1971.

Yost, W., and Neilsen, D. Fundamentals of Hearing. New York: Holt, Rinehart and Winston, 1977.

Young, E., and Tracy, J. "An Experimental Short Form of the SSW Test for Learning Disabled Children." Audiology Hearing Education 3 (1977) : 7-11. 
APPENDICES 
APPENDIX A

RAW SSW TEST SCORES OF DYSLEXIC CHILDREN

\begin{tabular}{|c|c|c|c|c|}
\hline Child No. & $\mathrm{R}-\mathrm{NC}$ & $\mathrm{R}-\mathrm{C}$ & $\mathrm{L}-\mathrm{C}$ & $\mathrm{L}-\mathrm{NC}$ \\
\hline $1(\mathrm{R})$ & 97.5 & 90.0 & 82.5 & 90.0 \\
\hline $2(R)$ & 95.0 & 95.0 & 82.5 & 95.0 \\
\hline 3 & 95.0 & 90.0 & 77.5 & 82.5 \\
\hline $4 \quad(R)$ & 92.5 & 80.0 & 72.5 & 90.0 \\
\hline 5 & 97.5 & 87.5 & 62.5 & 87.5 \\
\hline 6 & 95.0 & 87.5 & 75.0 & 95.0 \\
\hline 7 & 97.5 & 97.5 & 90.0 & 95.0 \\
\hline $8 \quad(R)$ & 92.5 & 87.5 & 68.5 & 92.5 \\
\hline 9 (R) & 95.0 & 90.0 & 87.5 & 97.5 \\
\hline $10(\mathrm{R})$ & 68.5 & 62.5 & 60.0 & 78.5 \\
\hline II (R) & 97.5 & 97.5 & 70.0 & 87.5 \\
\hline 12 & 90.0 & 70.0 & 55.0 & 97.5 \\
\hline 13 & 87.5 & 72.5 & 72.5 & 95.0 \\
\hline 14 & 92.5 & 85.0 & 47.5 & 100.0 \\
\hline 15 & 95.0 & 87.5 & 85.0 & 95.0 \\
\hline $16(\mathrm{R})$ & 95.0 & 87.5 & 72.5 & 87.5 \\
\hline 17 (R) & 92.5 & 55.0 & 65.0 & 90.0 \\
\hline $18 \quad(R)$ & 82.5 & 62.5 & 62.5 & 82.5 \\
\hline 19 & 95.0 & 60.0 & 100.0 & 100.0 \\
\hline $20 \quad(R)$ & 95.0 & 100.0 & 90.0 & 92.5 \\
\hline $21(R)$ & 97.5 & 92.5 & 72.5 & 97.5 \\
\hline
\end{tabular}




\section{APPENDIX B}

RAW SSW TEST SCORES OF MOTHERS

\begin{tabular}{crrrr}
\hline Family No. & R-NC & R-C & L-C & L-NC \\
\hline $1^{a}$ & 97.5 & 82.5 & 92.5 & 100.0 \\
2 & 100.0 & 100.0 & 97.5 & 100.0 \\
$4^{a}$ & 100.0 & 100.0 & 95.0 & 100.0 \\
5 & 97.5 & 100.0 & 65.0 & 97.5 \\
6 & 100.0 & 100.0 & 100.0 & 100.0 \\
7 & 100.0 & 100.0 & 100.0 & 100.0 \\
8 & 100.0 & 97.5 & 95.0 & 100.0 \\
$9^{a}$ & 100.0 & 100.0 & 100.0 & 100.0 \\
10 & 100.0 & 62.5 & 67.5 & 97.5 \\
11 & 100.0 & 97.5 & 92.5 & 95.0 \\
12 & 100.0 & 95.0 & 92.5 & 100.0 \\
$13^{a}$ & 100.0 & 100.0 & 100.0 & 100.0 \\
$14^{a}$ & 97.5 & 90.0 & 85.0 & 97.5 \\
15 & 97.5 & 97.5 & 90.0 & 100.0 \\
$16^{a}$ & 100.0 & 100.0 & 95.0 & 100.0 \\
\hline & 100.0 & 100.0 & 90.0 & 100.0 \\
\hline$a$ & 100 & & &
\end{tabular}

andicates affected parents. 


\section{APPENDIX C}

RAW SSW TEST SCORES OF FATHERS

\begin{tabular}{|c|c|c|c|c|}
\hline Family No. & $\mathrm{R}-\mathrm{NC}$ & $\mathrm{R}-\mathrm{C}$ & $\mathrm{L}-\mathrm{C}$ & $\mathrm{L}-\mathrm{NC}$ \\
\hline 1 & 97.5 & 92.5 & 92.5 & 97.5 \\
\hline 2 & 100.0 & 100.0 & 97.5 & 100.0 \\
\hline 3 & 100.0 & 100.0 & 100.0 & 100.0 \\
\hline $4^{a}$ & 92.5 & 87.5 & 92.5 & 95.0 \\
\hline $5^{a}$ & 92.5 & 90.0 & 82.5 & 97.5 \\
\hline 6 & 95.0 & 97.5 & 92.5 & 97.5 \\
\hline $7^{a}$ & 100.0 & 90.0 & 67.5 & 100.0 \\
\hline $8^{a}$ & 92.5 & 92.5 & 85.0 & 90.0 \\
\hline 9 & --- & --- & --- & --- \\
\hline $10^{\mathrm{a}}$ & 97.5 & 57.5 & 42.5 & 100.0 \\
\hline 11 & 100.0 & 100.0 & 97.5 & 100.0 \\
\hline 12 & 100.0 & 100.0 & 97.5 & 100.0 \\
\hline $13^{a}$ & 95.0 & 97.5 & 87.5 & 100.0 \\
\hline 14 & 100.0 & 100.0 & 100.0 & 100.0 \\
\hline $15^{\mathrm{a}}$ & 95.0 & 92.5 & 90.0 & 100.0 \\
\hline 16 & 100.0 & 100.0 & 95.0 & 97.5 \\
\hline
\end{tabular}

$a_{\text {Indicates affected parents. }}$ 
APPENDIX D

RAW SSW TEST SCORES OF NORMAL READING CHILDREN

\begin{tabular}{crrrr}
\hline Child No. & R-NC & R-C & L-C & \multicolumn{1}{c}{ I-NC } \\
\hline 1 & 100.0 & 92.5 & 65.0 & 95.0 \\
2 & 100.0 & 97.5 & 95.0 & 100.0 \\
3 & 100.0 & 100.0 & 95.0 & 100.0 \\
4 & 100.0 & 100.0 & 87.5 & 100.0 \\
5 & 100.0 & 90.0 & 85.0 & 95.0 \\
\hline
\end{tabular}




\section{APPENDIX E}

\section{DIFFERENCES IN SSW TEST SCORES OF DYSLEXIC CHILDREN AND INDIVIDUALIY AFFECTED AND NON-AFFECTED PARENTS IN LEFT COMPETING MODE}

\begin{tabular}{|c|c|c|}
\hline Child No. & $\begin{array}{c}\text { Affected } \\
\text { Minus Dyslexic }\end{array}$ & $\begin{array}{l}\text { Non-affected } \\
\text { Minus Dyslexic }\end{array}$ \\
\hline 1 & $2.5 \%$ & $2.5 \%$ \\
\hline 2 & $15.0 \%$ & $15.0 \%$ \\
\hline 3 & $17.5 \%$ & $22.5 \%$ \\
\hline 4 & $2.5 \%$ & $30.0 \%$ \\
\hline 5 & $-10.0 \%$ & $17.0 \%$ \\
\hline 6 & $-7.5 \%$ & $10.0 \%$ \\
\hline 7 & $24.0 \%$ & $31.5 \%$ \\
\hline 8 & $22.5 \%$ & $27.5 \%$ \\
\hline 9 & $-20.0 \%$ & $12.5 \%$ \\
\hline 10 & $7.5 \%$ & $35.0 \%$ \\
\hline 11 & $15.0 \%$ & 30.0 움 \\
\hline 12 & $-30.0 \%$ & $20.0 \%$ \\
\hline 13 & $40.0 \%$ & $45.0 \%$ \\
\hline 14 & $12.5 \%$ & $15.0 \%$ \\
\hline 15 & $12.5 \%$ & $15.0 \%$ \\
\hline 16 & $20.0 \%$ & $15.0 \%$ \\
\hline 17 & $27.5 \%$ & $37.5 \%$ \\
\hline 18 & $-10.0 \%$ & $-5.0 \%$ \\
\hline 19 & $0.0 \%$ & $5.0 \%$ \\
\hline 20 & $18.5 \%$ & $22.5 \%$ \\
\hline
\end{tabular}

